\title{
Iodine Status in the Elderly: Association with Milk Intake and Other Dietary Habits
}

\author{
Sara Watutantrige-Fernando ${ }^{1 *}$, Susi Barollo ${ }^{1}$, Loris Bertazza ${ }^{1}$, Francesca Sensi ${ }^{1}$, Elisabetta Cavedon ${ }^{1}$, \\ Simona Censi ${ }^{1}$, Nicola Veronese ${ }^{2}$, Filippo Ceccato ${ }^{1}$, Federica Vianello ${ }^{3}$, Marco Boscaro ${ }^{1}$, Davide \\ Nacamulli ${ }^{4}$, Valentina Camozzi ${ }^{1}$, Caterina Mian ${ }^{1}$ \\ ${ }^{1}$ Endocrinology Unit, Department of Medicine, University of Padua, Via Ospedale Civile n. 105, 35128 Padua, Italy \\ ${ }^{2}$ Geriatrics Division, Department of Medicine, University of Padua, Via Ospedale Civile n. 105, 35128 Padua, Italy \\ ${ }^{3}$ Radiotherapy Unit, Istituto Oncologico Veneto, IOV-IRCCS, Via Giustiniani n. 2, 35128 Padua, Italy \\ ${ }^{4}$ Endocrinology Unit, Department of Medicine, Padua General Hospital, Via Ospedale Civile n. 105, 35128 Padua, Italy
}

Received: December 23, 2016; Accepted: January 23, 2017; Published: February 27, 2017

*Corresponding author: Sara Watutantrige-Fernando, MD, Endocrinology Unit, Department of Medicine, University of Padua, Via Ospedale Civile n. 105, 35128 Padua, Italy; Tel: +39-04982134266; Fax: +39-049657391. E-mail: sara.watutantrige@gmail.com

\begin{abstract}
Background: Iodine deficiency is still an issue with important consequences, not only in younger people, but also in the elderly. We proposed to assess iodine status in elderly females, to analyze their eating habits and to compare results with our previous findings on female from childhood to fertile age.

Materials and Methods: This observational study that involved 189 menopausal women (51-86 years old) undergoing endocrinological evaluation at our center in the Veneto region, a northeast Italian area. We measured Urinary Iodine Concentration (UIC) from spot urine samples and participants were asked to fill in a food frequency questionnaire; we also collected data on bone metabolism from the hospital laboratory database network system.

Results: The median UIC of the sample as a whole was $30 \mu \mathrm{g} / \mathrm{l}$, corresponding to a moderate iodine deficiency. Among these subjects $47.7 \%$ were daily milk consumers: such women had a higher UIC than the occasional milk consumers (43 vs $30 \mu \mathrm{g} / \mathrm{l}, \mathrm{P}=0.0041$ ). Regarding other dietary habits, a great proportion of women resulted undernourished; moreover the declining trend in milk consumption with increasing age is similar to the age-related decline in UIC and 24h-Urinary Calcium (U-Ca).
\end{abstract}

Conclusions: women of menopausal age in our series were lacking in iodine because of reduced milk intake, in the contest of a major condition of global undernourishment. We confirm that milk is per se an important source of iodine if consumed in appropriate quantities.

Keywords: Iodine; UIC; Milk; Urinary calcium; Elderly

\section{Introduction}

Iodine deficiency is a problem seen worldwide, and it has been well documented that it is the "single most important preventable cause of brain damage" [1]. Even today, 30\% of school-aged children are thought to be iodine-deficient [2]. Iodine deficiency can have a spectrum of consequences of various severity and types, according to the entity of the deficiency, at all ages [3]. The most known and relevant consequence is represented by cognitive impairment responsible, particularly in high-income countries, for poor intellectual performances (e.g. a lower verbal and total Intelligence Quotient, poor reading accuracy and comprehension) [4]. At all ages, iodine deficiency can cause goiter, which is only reversible with iodine supplementation in younger people [5]. Iodine deficiency is also related to a greater susceptibility to nuclear radiation, and ensuring an optimal iodine intake can downgrade thyroid cancer to the less aggressive histotypes [6, 7]. In adults, the main disorders related to iodine deficiency include impaired mental function, reduced work productivity, and toxic nodular goiter. Studies in the literature have often concentrated on iodine deficiency in younger people, while limited data are available on the elderly. In 1998 Laurberg et al [8] focused on elderly subjects and found that the population iodine intake is an essential determinant of which types of thyroid disorders are common: indeed a deficient iodine intake, even mild or moderate, that is common in European countries, is related to goiter and thyroid hyperfunction, while a relative high iodine intake is related to impaired thyroid function. In the elderly, thyroid dysfunctions can have a more relevant clinical impact than in younger subjects, being the main dangers of hyperthyroidism atrial fibrillation (with the risk of reduced cardiac function and embolism) and osteoporosis, while lipid abnormalities with atherosclerosis in case of reduced thyroid function [9-11]. On the basis of these evidences, we concentrated our study on the elderly, particularly in a subset of menopausal women, because the elderly represent a considerable proportion of the general population thanks to an increasing life expectancy [12]. The aims of this study were: i) to assess iodine status in older women; ii) to analyze their eating habits; and iii) to compare the results with our previous findings on females, where we found a descendant trend in milk consumption, corresponding to descendant UIC values, starting from childhood to fertile age [13]. 


\section{Materials and Methods}

\section{Subjects}

From October 2015 to January 2016 we consecutively recruited 189 women of menopausal age undergoing endocrinological evaluation at our center in the Veneto region of north-eastern Italy (an area of mild iodine deficiency) [14]. All participants were invited to complete a food frequency questionnaire consisting of two parts: 1) the first recorded date and place of birth, personal history of kidney insufficiency or intestinal malabsorption, recent exposure to iodine contrast media, thyroid diseases, use of iodine-containing products (food supplements, medicines); 2) the second consisted of a food frequency questionnaire concerning whether they used iodized salt and, if so, for how many years they had done so, and asking a quantification of a wide series of food, typically included in our diet, such as their daily dietary intake of cow's milk, yoghurt, cheese, meat, eggs, fish, and soy milk. Milk intake was scored as: 0 for no milk; 1 for occasional consumption; 2 for one cup a day; and 3 for more than 1 cup a day. The intake of yoghurt, cheese, meat, eggs, fish, and own production aliments was scored as: never (0), at least once a week (1), more than once a week (2). The use of iodized salt, cassava, cabbage, turnips, mustard, horseradish, seaweed, estro-progestinic drugs, and smoking were scored as YES or NO. Although beyond the purposes of this study, assuming a global malnutrition in this subset of women in the light of the preliminary data regarding iodine status and dietary habits, we collected data on bone metabolism from the hospital laboratory database network system: vitamin D values were expressed as nmol/l (normal: 75-250) and 24h-urinary calcium (U-Ca) values as ng/24 h (normal: 100-300). Participants collected $20 \mathrm{ml}$ spot urine samples in the morning, which were divided into aliquots and kept refrigerated below $20^{\circ} \mathrm{C}$ until the time of assay. The Urinary Iodine Concentration (UIC) was expressed as $\mu \mathrm{g} / \mathrm{l}$ and was measured in duplicate using the colorimetric ceric ion arsenious acid method in a second-generation Technicon Auto-Analyzer (Brain Luebbe GmbH, Germany) [15]. The intra- and inter-assay coefficients of variation were $5.7 \%$ and $5.5 \%$, respectively. The study was conducted according to the guidelines laid down in the Declaration of Helsinki; verbal informed consent was obtained from all participants, and was witnessed and formally recorded; the present study was notified to our Local Ethical Committee (Azienda Ospedaliera di Padova, code number: 0029374).

\section{Statistical analysis}

The Kolmogorov-Smirnov test was used to test the normal distribution of the UIC: the values were not normally distributed, so they are given as medians and 95\% Confidence Intervals (CI); the vitamin D and U-Ca values were normally distributed. The Mann-Whitney test was used to study the differences in UIC visà-vis the use of iodized salt, milk intake, and U-Ca and vitamin D levels. The chi-square test was used to explore the relationship between adequate iodine status (adopting the WHO's UIC cutoff of $\geq 100 \mu \mathrm{g} / \mathrm{l}$ ) and dietary habits and bone metabolism parameters. A P value $<0.05$ was considered statistically significant.

\section{Results}

The women were a mean 66 years of age ( $\min 51$, max 86), and their median UIC was $30 \mu \mathrm{g} / \mathrm{l}(\min 22$, $\max 542 ; 95 \%$ CI $30-35$ $\mu \mathrm{g} / \mathrm{l})$; according to the WHO classification, $34 / 189$ (18\%) women were mildly deficient and 113/189 (60\%) were moderately iodine deficient, moreover we found no severely iodine deficient women. Their clinical data and dietary habits are shown in Table 1. Concerning available eating habits, 53/174 women (30.5\%) did not drink milk, 38/174 (21.8\%) did so occasionally, 72/174 (41.4\%) drank 1 cup a day, and 11/174 (6.3\%) drank more than 1 cup a day. On the whole, 139/174 women (80\%) had a UIC $<100 \mu \mathrm{g} / \mathrm{l}$. The daily cow's milk consumers had a median UIC of $44 \mu \mathrm{g} / \mathrm{l}$, while for the occasional milk drinkers it was $30 \mu \mathrm{g} / \mathrm{l}(\mathrm{P}=$ 0.0041 ); among the women with a UIC $\geq 100 \mu \mathrm{g} / \mathrm{l}, 69 \%$ were daily milk consumers whereas among those with a UIC $<100 \mu \mathrm{g} / \mathrm{l}, 42 \%$ uses it regularly $(\mathrm{P}=0.01)$.

Data on iodized salt use was available for 187 women of

Table 1: Clinical data and dietary habits

\begin{tabular}{|c|c|c|c|c|}
\hline & Score & $\begin{array}{c}\text { Iodine-deficient } \\
\text { subjects } \\
\text { (UIC }<100 \mu \mathrm{g} / \mathrm{l} \text { ) }\end{array}$ & $\begin{array}{c}\begin{array}{c}\text { Iodine-sufficient } \\
\text { subjects }\end{array} \\
\text { (UIC } \geq 100 \mu \mathrm{g} / \mathrm{l})\end{array}$ & P value \\
\hline Age (years) & & $65.70 \pm 8.68$ & $67.00 \pm 7.57$ & 0.370 \\
\hline \multirow[t]{2}{*}{ Milk intake } & Score $0-1$ & $80 / 139(57.55 \%)$ & $11 / 35$ (31.42\%) & \multirow{2}{*}{0.01} \\
\hline & Score 2-3 & $59 / 139(42.44 \%)$ & $24 / 35$ (68.57\%) & \\
\hline \multirow{3}{*}{ Chicken meat } & Score 0 & $7 / 143(4.89 \%)$ & $4 / 35(11.42 \%)$ & \multirow{3}{*}{0.302} \\
\hline & Score 1 & $78 / 143(54.54 \%)$ & $16 / 35(45.71 \%)$ & \\
\hline & Score 2 & $58 / 143(40.55 \%)$ & $15 / 35(42.85 \%)$ & \\
\hline \multirow{3}{*}{ Yogurt } & Score 0 & 45/136 (33.08\%) & $9 / 36(25 \%)$ & \multirow{3}{*}{0.561} \\
\hline & Score 1 & 49/136 (36.02\%) & $13 / 36(36.11 \%)$ & \\
\hline & Score 2 & $42 / 136(30.88 \%)$ & $14 / 36(32.88 \%)$ & \\
\hline \multirow{3}{*}{ Red meat } & Score 0 & 18/144 (12.50\%) & $3 / 35(8.57 \%)$ & \multirow{3}{*}{0.654} \\
\hline & Score 1 & 83/144 (57.63\%) & $23 / 35(65.71 \%)$ & \\
\hline & Score 2 & 43/144 (29.86\%) & 9/35 (25.71\%) & \\
\hline \multirow{3}{*}{ Cheese } & Score 0 & $2 / 143(1.39 \%)$ & $0 / 37(0 \%)$ & \multirow{3}{*}{0.517} \\
\hline & Score 1 & 49/143 (34.26\%) & $10 / 37(27.02 \%)$ & \\
\hline & Score 2 & $92 / 143(64.33 \%)$ & $27 / 37(72.97 \%)$ & \\
\hline \multirow{3}{*}{ Eggs } & Score 0 & 12/143 (8.39\%) & $2 / 35(11.42 \%)$ & \multirow{3}{*}{0.816} \\
\hline & Score 1 & $128 / 143(89.51 \%)$ & $30 / 35$ (85.71\%) & \\
\hline & Score 2 & $3 / 143(2.09 \%)$ & $1 / 35(2.85 \%)$ & \\
\hline \multirow{3}{*}{ Fish } & Score 0 & $21 / 144(14.58 \%)$ & 4/36 (11.11\%) & \multirow{3}{*}{0.859} \\
\hline & Score 1 & $101 / 144(70.13 \%)$ & $26 / 36(72.22 \%)$ & \\
\hline & Score 2 & $22 / 144$ (15.27\%) & $6 / 36(16.66 \%)$ & \\
\hline \multirow[t]{2}{*}{ Iodized salt } & YES & $88 / 149$ (59.06\%) & $24 / 38(63.15 \%)$ & \multirow{2}{*}{0.783} \\
\hline & NO & $61 / 149(40.93 \%)$ & $14 / 38(36.84 \%)$ & \\
\hline $\begin{array}{l}\text { Vitamin D } \\
\text { (nmol/l) }\end{array}$ & & $88.73 \pm 25.05$ & $85.96 \pm 33.06$ & 0.157 \\
\hline U-Ca (ng/24h) & & $140.09 \pm 89.14$ & $175.10 \pm 68.03$ & 0.398 \\
\hline
\end{tabular}


whom 112 (59.9\%) used it regularly: 149/187 (79.7\%) had a UIC $<100 \mu \mathrm{g} / \mathrm{l}$. The UIC of iodized salt users did not differ significantly from that of non-users $(30 \mu \mathrm{g} / \mathrm{l}$ in both groups, $\mathrm{P}=0.587)$. No significant association emerged between UIC and time since starting to use iodized salt.

No significant associations were found between UIC and consumption of dairy products, fish, beef or chicken meat, or other individual characteristics (kidney insufficiency, intestinal malabsorption, recent use of iodine contrast media, thyroid disorders, iodine drugs or supplements, smoking habits).

Regarding eating habits, the women declared to consume once a week or less or not at all the entire range of food evaluated (score 0-1): 116/172 (67\%) reported a score 0-1 for yogurt, $105 / 178$ (59\%) for chicken, 127/179 (71\%) for beef, 174/178 (98\%) for eggs and $152 / 180$ (84\%) for fish; despite other products cheese was consumed more than once a week by $119 / 180$ women $(66 \%)$.

Regarding bone metabolism, we were able to collect data on 40 subjects. Their mean vitamin D level was $88.16 \mathrm{nmol} / \mathrm{l}$ (min 38, max 171; 95\% CI 76.23-95.22) and their mean U-Ca level was 152 ng/24h (min 7.6, $\max 328 ; 95 \%$ CI 126.03-178.42). There were $15 / 40$ women (37.5\%) with U-Ca levels below the normal limit, 23/40 (57.5\%) had normal U-Ca levels, and 2/40 (5\%) had excessive U-Ca levels.

The UIC of the subjects with normal U-Ca levels did not significantly differ from that of the hypocalciuric subjects (with $36.6 \mu \mathrm{g} / \mathrm{l}$ and $30 \mu \mathrm{g} / \mathrm{l}$, respectively; $\mathrm{P}=0.213$ ). As a whole, the proportions of hypocalciuric subjects differed significantly by UIC, however: $9 / 10$ women (90\%) with an adequate UIC had normal U-Ca levels, whereas this proportion was lower $(14 / 30$, $46.7 \%)$ among the iodine-deficient subjects $(\mathrm{P}<0.05$, Figure 1$)$. As for the association between milk consumption and U-Ca, 16/22 daily milk consumers $(72.72 \%)$ had normal U-Ca levels, while 9/18 occasional or non-consumers $(50 \%)$ were normocalciuric $(\mathrm{P}=0.15)$. No significant association emerged between UIC and vitamin D levels.

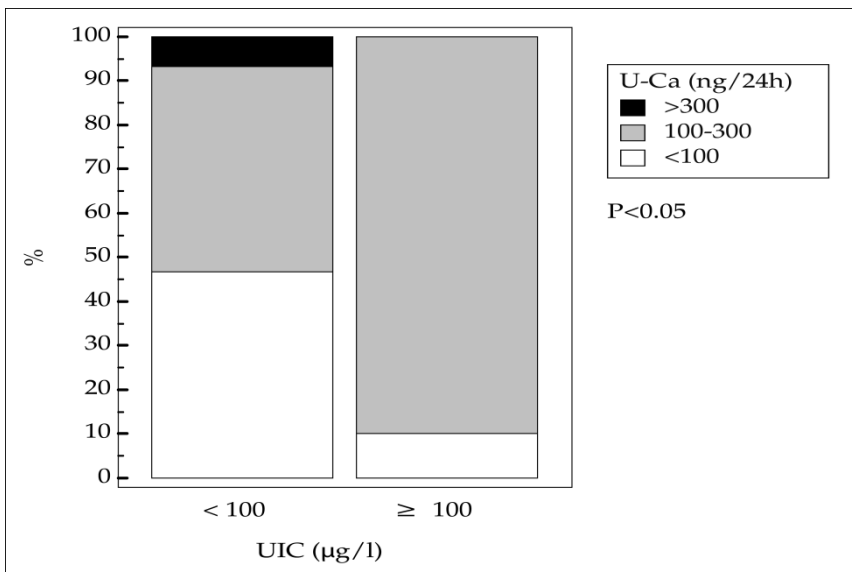

Figure 1: Relationship between urinary iodine concentration (UIC) and $24 \mathrm{~h}$ urinary calcium (U-Ca).

\section{Discussion}

In the last few decades many social and economic steps have been taken to promote iodine prophylaxis because iodine deficiency can have severe consequences for people of any age. Some population groups are particularly vulnerable to iodine deficiency, primarily fetuses/neonates and pregnant/lactating women. Iodine is important because it is a constituent of thyroid hormones that are essential to the development of the central nervous system. In 2013, Raymann et al [4] studied 1,040 motherchild pairs, matching mothers' iodine status in the first trimester of gestation with data on the cognitive outcomes of their 8- to 9-year-old children. They demonstrated that children born of iodine-deficient mothers had a worse cognitive status. Apart from these particularly susceptible groups, iodine deficiency can also negatively affect adults in a number of ways, the most important of which is a greater probability of developing goiter. There is a paucity of information in the literature on iodine status in the elderly, probably because some structural glandular changes are so established and irreversible in adult age that correcting iodine status could well be irrelevant. The Pescopagano study [5] clearly demonstrated that improving iodine status only reduced the frequency of nodular goiter in younger people because of the irreversible fibrotic changes occurring in longstanding goiter. In some published reports, iodine status in the elderly was considered as part of broader population-based studies: judging from these surveys, individuals from 60 years old onwards seem to have a lower UIC than other age groups. Zou et al [16] published a cross-sectional study on iodine status comparing rural and urban residents in a Chinese Province: they concluded that the rural population had a higher UIC than the city dwellers (170.1 $\mu \mathrm{g} / \mathrm{l}$ versus $153.5 \mu \mathrm{g} / \mathrm{l}$ ). Concentrating on iodine status by age, the UIC was $154 \mu \mathrm{g} / \mathrm{l}$ for the elderly rural residents, and $129.5 \mu \mathrm{g} / \mathrm{l}$ for the elderly urban population. Much the same results emerged from a cross-sectional study conducted in Spain [17]: this survey confirmed that people $>65$ years old had a significantly lower UIC than the younger age groups $(109.33 \mu \mathrm{g} / \mathrm{l}$ versus $161.52 \mu \mathrm{g} / \mathrm{l})$. A study conducted by Tang [18] in Taiwan 5 years after mandatory salt iodization was stopped also showed that older individuals had a lower UIC level than younger people $(88 \mu \mathrm{g} / \mathrm{l}$ versus 100 $\mu \mathrm{g} / \mathrm{l})$, and this was particularly evident in older females $(79 \mu \mathrm{g} / \mathrm{l})$. In the light of these studies, we analyzed iodine status in women of menopausal age, collecting 188 urine samples and questionnaires on individual dietary habits. All the women were residents of the Veneto region, an area of mild iodine deficiency (median UIC $81 \mu \mathrm{g} / \mathrm{l}$ ), with some differences between the mountainous, hilly and lowland areas (where the median UIC is 94, 54, and $77 \mu \mathrm{g} / \mathrm{l}$, respectively) [14]. The median UIC for our sample as a whole was $30 \mu \mathrm{g} / \mathrm{l}$, indicative of a moderate iodine deficiency according to the WHO classification [1]. When we investigated cow's milk consumption, we found that more than $50 \%$ of the women drank milk only occasionally. Comparing these data with our previous findings in younger females in various age brackets [13], we identified a global declining trend in the consumption of cow's milk with age: while the majority of 4-year-olds and 12-year-olds drank milk daily $(73.42 \%$ and $62.30 \%$, respectively), women of fertile and menopausal age were less likely to drink milk every day (55.08\% and 47.7\%, respectively, $\mathrm{P}<0.0001$ ) (Figure 2). 
There may be several explanations for these different dietary habits: 1) younger people, and infants in particular, are used to drinking milk as a natural continuation of lactation; 2) milk is rich in nutrients and parents consider it important to ensure that their children (even in adolescence) have an adequate intake of minerals, proteins and vitamins; 3) as they grow up, children and adolescents gradually change their dietary habits, acquiring personal tastes and different lifestyles; 4) being rich in nutrients, milk is also rich in cholesterol and, in adulthood, many people tend to exclude it from their diet to avoid hypercholesterolemia and reduce the related cardiovascular risks. Moreover, some Authors associate its consumption to many other diseases, the most significant of which is cancer $[19,20]$. The low milk consumption identified in the elderly is in line with the declining trend in people's UIC with age (Figure 3 ), since milk consumption was confirmed as the only factor influencing the UIC in this subset of subjects too.

Daily cow's milk consumption was associated with a significantly higher median UIC in our series of elderly women (44 versus $30 \mu \mathrm{g} / \mathrm{l}, \mathrm{P}=0.004$ ), but the small difference in UIC between milk consumers and non-consumers in our sample goes to show that even drinking milk daily cannot assure an optimal UIC. One in two of our subjects $(83 / 174,47.7 \%)$ were used to drinking milk daily, but only $28.9 \%$ of them had an adequate UIC. This could relate to the fact that we did not ascertain how much milk they drank in absolute terms, and it is likely that the elderly drank smaller volumes of milk than younger people. Daily milk consumption coincided with an adequate iodine status in all female subgroups, irrespective of age, in a previous study of ours [13], but not in the present case. Hypothesizing an inadequate nutrient intake, we analyzed our sample's other dietary habits: we found that a considerable proportion of the women consumed the other foods investigated only occasionally or not at all (yogurt $67 \%$, chicken $59 \%$, beef $71 \%$, eggs $98 \%$, fish $84 \%$ ). Taking a wider

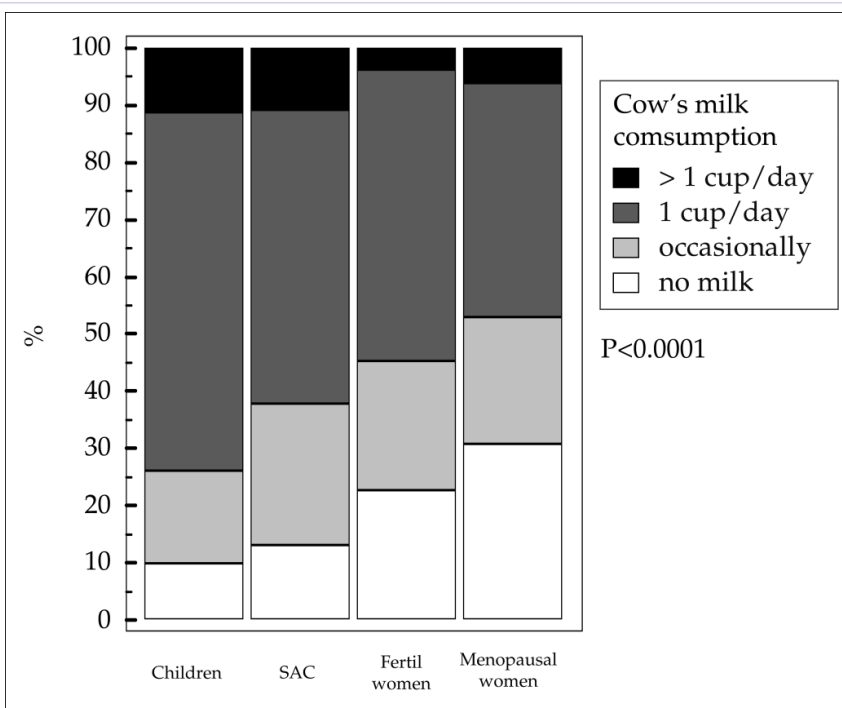

Figure 2: Milk consumption among female groups (Children; SAC: School age children; Fertile women, Menopausal women).

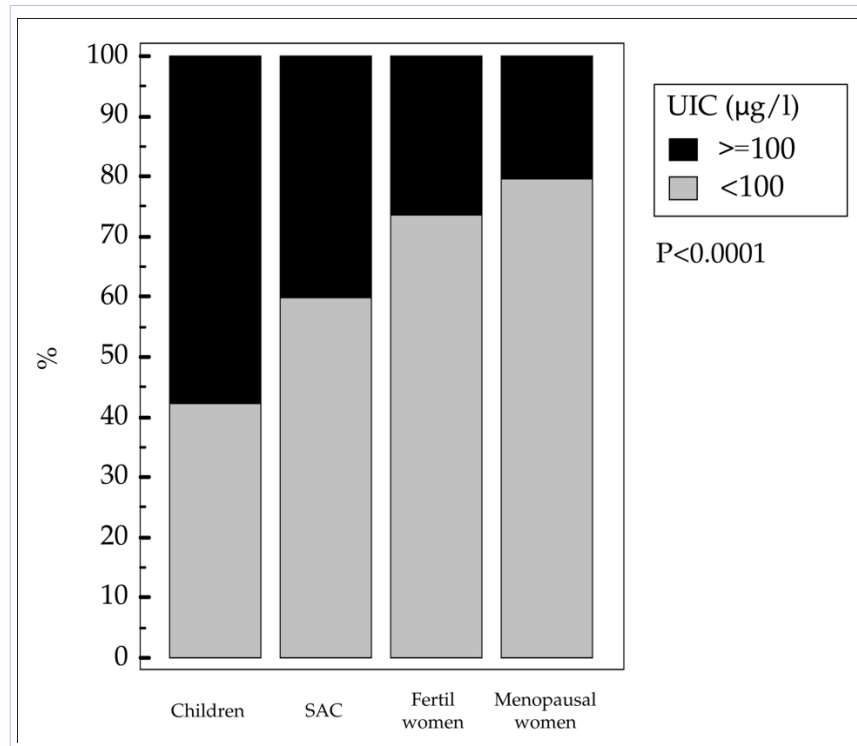

Figure 3: Urinary iodine concentration (UIC) distribution among female groups (Children; SAC: School age children; Fertile women, Menopausal women).

point of view, to confirm a comprehensive malnutrition state, we analyzed, where available, data on bone metabolism (U-Ca and vitamin D) from the hospital laboratory database network system and we assessed U-Ca levels as a marker of milk intake and an indirect indicator of iodine intake, given that milk is an important source of iodine and calcium [21]. Although a single UIC value from spot urine samples does not allow to extrapolate the real iodine status of a done single subject, we observed that among our subjects with low U-Ca levels, the vast majority (93.33\%) were also iodine-deficient, whereas $90 \%$ of the women with an adequate iodine status also had good U-Ca levels. These findings suggest that the iodine deficiency identified in the elderly relates to a limited global consumption of milk (even among those who drink milk daily). In addition, a limited milk consumption was also associated with a broader deficiency of several nutrients. Elderly people tend to gradually eat less for numerous reasons, including loss of appetite, gustatory dysfunctions, declining basal metabolism, and economic issues too [22, 23].

Iodized salt was used by $59.9 \%$ of the women in our sample, but we found no significant difference in terms of UIC between users and non-users. This proportion of users is similar to the figure identified in our previous study (in 2011), suggesting that our iodine prophylaxis program has yet to reached the target $90 \%$ coverage [24]. Among the women who were using iodized salt, the proportion of iodine-sufficient individuals was only $21.42 \%$; in other words, even regular iodized salt consumption is unable to assure an optimal iodine intake. This could be due to the inappropriate storage of iodized salt and to part of the iodine in the salt being lost during cooking processes.

Hyperthyroidism is known to be more common in areas of mild-to-moderate iodine deficiency than in areas of severe iodine deficiency, where hypothyroidism typically occurs. A higher incidence of hyperthyroidism is positively associated 
with the incidence of toxic multinodular goiter [25] because iodine deficiency promotes the growth of clusters of autonomous thyrocytes, resulting in the overproduction of thyroid hormones. Correcting iodine deficiency in the elderly could help to reduce this autonomization process, leading to a normalization of TSH and thyroid hormones, containing the cardiovascular and skeletal consequences of hyperthyroidism in a particularly vulnerable and susceptible population.

We conclude that iodine deficiency is still an issue that affects a sizable part of the population, including the elderly. We should continue to educate people to consume products rich in iodine, such as iodized salt and cow's milk, emphasizing that the iodine content of such foodstuffs may be lost with storage and cooking, and may be insufficient. We should also pay attention to ensuring that the elderly maintain an adequate iodine status to avoid preventable cardiovascular consequences related to hyperthyroidism.

\section{Acknowledgement}

We thank Frances Coburn for text editing, and Dina Pozza for help in storing and analyzing the urine samples.

\section{References}

1. WHO, UNICEF, ICCID. Assessment of iodine deficiency disorders and monitoring their elimination. $3^{\text {rd }}$ ed. WHO press. Geneva. 2007

2. Pearce EN, Andersson M, Zimmermann MB. Global iodine nutrition: where do we stand in 2013? Thyroid. 2013;23(5):523-528.

3. WHO, UNICEF, ICCIDD. Indicators for assessing iodine deficiency disorders and their control through salt iodization. In: Assessment of iodine deficiency disorders and monitoring their elimination, World Health Organization. Geneva.WHO Press. 1994.

4. Bath SC, Steer CD, Golding J, Emmett P, Raymann MP. Effect of inadequate iodine status in UK pregnant women on cognitive outcomes in their children: results from the Avon Longitudinal Study of Parents and Children (ALSPAC). The Lancet. 2013;382:331-337.

5. Aghini Lombardi F, Fiore E, Tonacchera M, Antonangeli L, Rago T, Frigeri $\mathrm{M}$, et al. The effect of voluntary iodine prophylaxis in a small rural community: the Pescopagano survey 15 years later. J Clin Endocrinol Metab. 2013;98(3):1031-1039.

6. Lind P, Langsteger W, Molnar M, Gallowitsch HJ, Mikosch P, Gomez I. Epidemiology of thyroid diseases in iodine sufficiency. Thyroid. 1998;8(12):1179-1183.

7. Farahati J, Geling M, Mäder U et al. Changing trends of incidence and prognosis of thyroid carcinoma in lower Franconia, Germany, from 1981-1995. Thyroid. 2004;14(2):141-147.

8. Laurberg P, Pedersen KM, Hreidarsson A, Sigfusson N, Iversen E, Knudsen PR. Iodine intake and the pattern of thyroid disorders: a comparative epidemiological study of thyroid abnormalities in the elderly in Iceland and in Jutland, Denmark. J Clin Endocrinol Metab. 1998;83(3):765-769.

9. Sawin CT, Geller A, Wolf PA, Belanger AJ, Baker E, Bacharach P, et al. Low serum thyrotropin concentrations as a risk factor for atrial fibrillation in older persons. N Engl J Med. 1994;331(19):1249-1252.
10. Mosekilde L, Eriksen EF, Charles P. Effects of thyroid hormones on bone and mineral metabolism. Endocrinol Metab Clin North Am. 1990;19(1):35-62.

11. Cooper DS, Halpern R, Wood LC, Levin AA, Ridgway EC. L-thyroxine therapy in subclinical hypothyroidism. A double-blind, placebocontrolled trial. Ann Intern Med. 1984;101(1):18-24.

12. GBD 2013 DALYs and HALE Collaborators, Murray CJ, Barber RM, Foreman KJ, Abbasoglu Ozgoren A, Abd-Allah F, et al. Global, regional, and national disability-adjusted life years (DALYs) for 306 diseases and injuries and healthy life expectancy (HALE) for 188 countries, 1990-2013: quantifying the epidemiological transition. Lancet. 2015;386(10009):2145-2191.

13. Watutantrige-Fernando S, Cavedon E, Nacamulli D, Pozza D, Ermolao A, Zaccaria M, et al. Iodine status from childhood to adulthood in females living in North-East Italy: Iodine deficiency is still an issue. Eur J Nutr. 2016;55(1):335-340.

14. Watutantrige-Fernando S, Barollo S, Nacamulli D, Pozza D, Giachetti $\mathrm{M}$, Frigato $\mathrm{F}$, et al. Iodine status in schoolchildren living in northeast Italy: the importance of iodized salt use and milk consumption. Eur J Clin Nutr. 2013;67(4):366-370.

15. Garry PJ, Lashey DW, Owen GM. Automated measurement of urinary iodine. Clin Chem. 1973;19(9):950-953.

16. Zou Y, Lou X, Ding G, Mo Z, Zhu W, Mao G. A cross-sectional comparison study on the iodine nutritional status between rural and urban residents in Zhejiang Province, China. BMJ Open. 2014;4(6):e005484.

17. Olmedo Carrillo P, García Fuentes E, Gutiérrez Alcántara C, Serrano Quero M, Moreno Martínez M, Ureña Fernández T, et al. Assessment of iodine nutritional status in the general population in the province of Jaén. Endocrinol Nutr. 2015;62(8):373-379.

18. Tang KT, Wang FF, Pan WH et al. Iodine status of adults in Taiwan 2005-2008, 5 years after the cessation of mandatory salt iodization. J Formos Med Assoc. 2016;115(8):645-651.

19. Markey O, Vasilopoulou D, Givens DI, Lovegrove JA. Dairy and cardiovascular health: Friend or foe?. Nutr Bull. 2014;39(2):161-171.

20. Melnik BC. Milk--the promoter of chronic Western diseases. Med. Hypotheses. 2009;72(6):631-639.

21. Girelli ME, Coin P, Mian C, Nacamulli D, Zambonin L, Piccolo M, et al. Milk represents an important source of iodine in schoolchildren of the Veneto region, Italy. J Endocrinol Invest. 2004;27(8):709-713.

22. Donini LM, Scardella P, Piombo L, Neri B, Asprino R, Proietti AR, et al. Malnutrition in elderly: social and economic determinants. J Nutr Health Aging. 2013;17(1):9-15.

23. Imoscopi A, Inelmen EM, Sergi G, Miotto F, Manzato E. Taste loss in the elderly: epidemiology, causes and consequences. Aging Clin Exp Res. 2012;24(6):570-579.

24.Zimmermann MB. Iodine deficiency. Endocr Rev. 2009;30:376-408.

25. Carlé A, Pedersen IB, Knudsen N, Perrild H, Ovesen L, Rasmussen LB, et al. Epidemiology of subtypes of hyperthyroidism in Denmark: a population-based study. Eur J Endocrinol. 2011;164(5):801-809. 